\title{
Effect of Multi Wall Carbon Nanotube Content on The Electrical and Rheological Properties of Polypropylene-based Nanocomposites
}

\author{
B. Afrinaldi ${ }^{1,2, *}$, A.L. Juwono ${ }^{2}$, C. Liza $^{1}$, S.J.A. Nasiri ${ }^{1}$ \\ ${ }^{1}$ Center of Polymer Technology, $460^{\text {th }}$ Bld Puspiptek Area, Indonesia \\ ${ }^{2}$ Physics Department, University of Indonesia, Indonesia
}

\begin{abstract}
Incorporating multi wall carbon nanotube (MWCNT) into the polymer can improve the electrical properties of the nanocomposites. The effects of MWCNT on the electrical and rheological properties of polypropylene/MWCNT (PP/MWCNT) nanocomposites are investigated. The nanocomposites were prepared using melt mixing technique at chamber temperature of $180^{\circ} \mathrm{C}$ and rotor rotation of $100 \mathrm{rpm}$ for 10 minutes. Addition of MWCNT increases the electrical surface conductivity up to $10^{-7} \mathrm{~S}$. The electrical percolation threshold of the nanocomposites is found to occur at $1.3 \mathrm{wt} \%$ MWCNT content. Viscosity of the nanocomposites increased with the addition of MWCNT. The rheological percolation threshold of the PP/MWCNT is found occur at $1.4 \mathrm{wt} \%$ MWCNT content. Well dispersion is observed by mean Scanning Electron Microscope (SEM) analysis.
\end{abstract}

\section{Introduction}

Carbon nanotubes (CNT) is a material that widely studied since their discovery by Iijima [1]. This is because the advantage of CNT which has a high aspect ratio so that increases the mechanical strength of the composites [2,3]. In addition, CNT also has other advantage such as a relatively high electrical conductivity [4].

Generally, polymer is an insulator material because it has a low conductivity $\left(>10^{-14} \mathrm{~S}\right)$. Therefore, polymer usually used as the isolator for cable. However, by addition CNT into the polymer can increase its conductivity. Some promising applications for this material are antistatic coating, energy storage devices, and electromagnetic interference shielding [5].

Dispersion of CNTs in a polymer matrix is one of the keys to improve electrical and mechanical properties of the nanocomposites. Some techniques were using compatibilizer such as PP-g-MA [6], in-situ polymerization of polyolefin with CNT [7,8], and by modification of the CNT's surface [9].

Previous research applied the acid treatment on the CNT that can improve the percolation threshold to $1.5 \mathrm{wt} \%$ [10]. The other research studied the effect of glycidyl methacrylate grafted MWCNT on polypropylene nanocomposites [11].

\footnotetext{
*Corresponding author: bambang@sentrapolimer.id
} 
In this work, the effect of MWCNT addition in nanocomposite PP/MWCNT in order to improve electrical and rheological properties with PP-g-MA compatibilizer produced by melt mixing technique is studied and investigated. The results are analyzed using insulation tester, rotational rheometer, and SEM.

\section{Methodology}

\subsection{Materials}

Polypropylene (PP HI10HO) from PT. Chandra Asri Petrochemical Tbk with MFR of 10 $\mathrm{g} / 10 \mathrm{~min}$ was used as matrix. Maleic anhydride modified polypropylene (Epolene ${ }^{\circledR} \mathrm{E}-43$ Wax) from Eastman was added for improving dispersion of CNT. Antioxidant (Irganox B215 FF) from BASF was used to avoid material degradation. The multi-wall carbon nanotube (MWCNT) from Cheaptubes with outer diameter of 30-50 nm and length of 10$20 \mu \mathrm{m}$ was utilized as the nanoscale filler.

\subsection{Sample preparation and characterization}

Masterbatch preparation was prepared by the addition of $10 \mathrm{wt} \%$ MWCNT and $5 \mathrm{wt} \% \mathrm{PP}$ g-MA in PP matrix. Masterbatch was mixed in Haake Rheomix PolyDrive at chamber temperature of $180^{\circ} \mathrm{C}$ and rotor rotation of $100 \mathrm{rpm}$ for 10 minutes. The similar process condition was applied to fabricate $\mathrm{PP} / \mathrm{MWCNT}$ nanocomposites. The masterbatch was added to obtain the composition shown in Table 1.

Table 1. Composition and abbreviations of the nanocomposites.

\begin{tabular}{|c|c|}
\hline Composition of nanocomposites & Abbreviation \\
\hline Neat PP & PP \\
\hline $\mathrm{PP}+3 \mathrm{wt} \%$ PP-g-MA & PP-MA3 \\
\hline PP $+3 w t \%$ PP-g-MA + $0.2 w t \%$ MWCNT & PP-MA3-CNT0.2 \\
\hline $\mathrm{PP}+3 \mathrm{wt} \%$ PP-g-MA + $0.4 \mathrm{wt} \%$ MWCNT & PP-MA3-CNT0.4 \\
\hline $\mathrm{PP}+3 \mathrm{wt} \%$ PP-g-MA + $0.6 \mathrm{wt} \%$ MWCNT & PP-MA3-CNT0.6 \\
\hline PP + $3 w t \%$ PP-g-MA + $0.8 w t \%$ MWCNT & PP-MA3-CNT0.8 \\
\hline PP $+3 w t \%$ PP-g-MA + $1.0 w t \%$ MWCNT & PP-MA3-CNT1.0 \\
\hline $\mathrm{PP}+3 \mathrm{wt} \%$ PP-g-MA + $1.2 \mathrm{wt} \% \mathrm{MWCNT}$ & PP-MA3-CNT1.2 \\
\hline PP $+3 w t \%$ PP-g-MA + $1.4 w t \%$ MWCNT & PP-MA3-CNT1.4 \\
\hline PP $+3 w t \%$ PP-g-MA + $1.6 w t \%$ MWCNT & PP-MA3-CNT1.6 \\
\hline PP $+3 w t \%$ PP-g-MA + $1.8 w t \%$ MWCNT & PP-MA3-CNT1.8 \\
\hline $\mathrm{PP}+3 \mathrm{wt} \%$ PP-g-MA + $2.0 \mathrm{wt} \% \mathrm{MWCNT}$ & PP-MA3-CNT2.0 \\
\hline
\end{tabular}

Electrical conductivity of the nanocomposites was measured at room temperature with Insulation tester UNILAP ISO $5 \mathrm{kV}$ based on ASTM D257. Rheological properties were performed on Rotational Rheometer MARS III using oscillatory frequency sweep at strain of 0.5 and temperature of $180^{\circ} \mathrm{C}$. Surface fractured of the nanocomposites was coated with Platinum and then observed using Scanning Electron Microscope (SEM) JEOL JSM-6510 at 10,000 magnification. 


\section{Results and discussion}

\subsection{Electrical properties}

Figure 1 shows that the percolation threshold of nanocomposites was occurred at $1.4 \mathrm{wt} \%$ MWCNT. Percolation threshold was described when the conductivity value of nanocomposites increases several orders of magnitude attributes to the continuous conducting networks formation. After the percolation, conductivity of the nanocomposites was saturated due to the interconnected conductive network structure $[5,12]$

The electrical percolation threshold of the PP/MWCNT nanocomposites was calculated with a power law function $[2,13,14]$ :

$$
\sigma=\sigma_{0}\left(\varphi-\varphi_{c}\right)^{\beta}
$$

where $\sigma$ is the electrical conductivity of the nanocomposites, $\sigma_{0}$ is a constant related to intrinsic conductivity, $\varphi$ is the volume fraction of the filler, $\varphi_{c}$ is a percolation threshold, and $\beta$ is the critical exponent. Based on linear regression shown in Figure 2, gives intercept, $\left(\sigma_{0}\right)=1.37 \times 10^{-7} \mathrm{~S}, \varphi_{\mathrm{c}}=1.3 \mathrm{wt} \%$, and slope $(\beta)=0.13$.

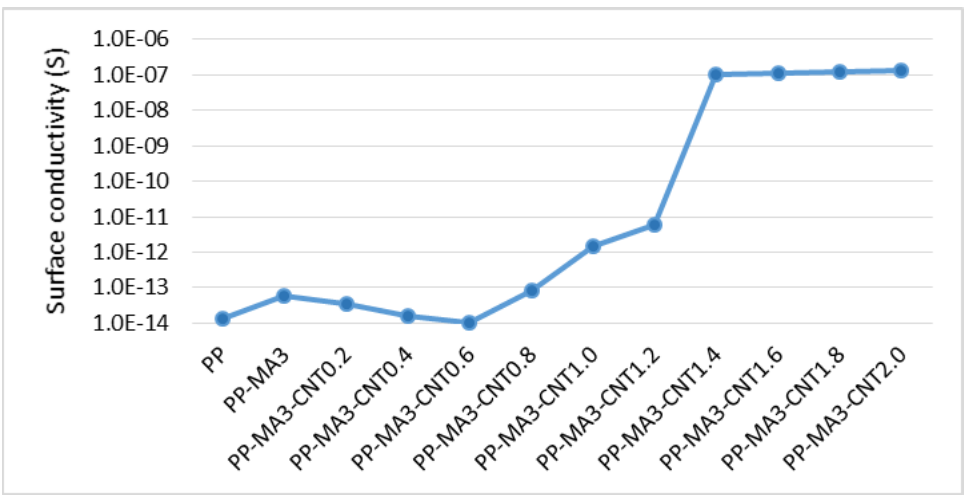

Fig. 1. Surface conductivity of PP/MWCNT nanocomposites.

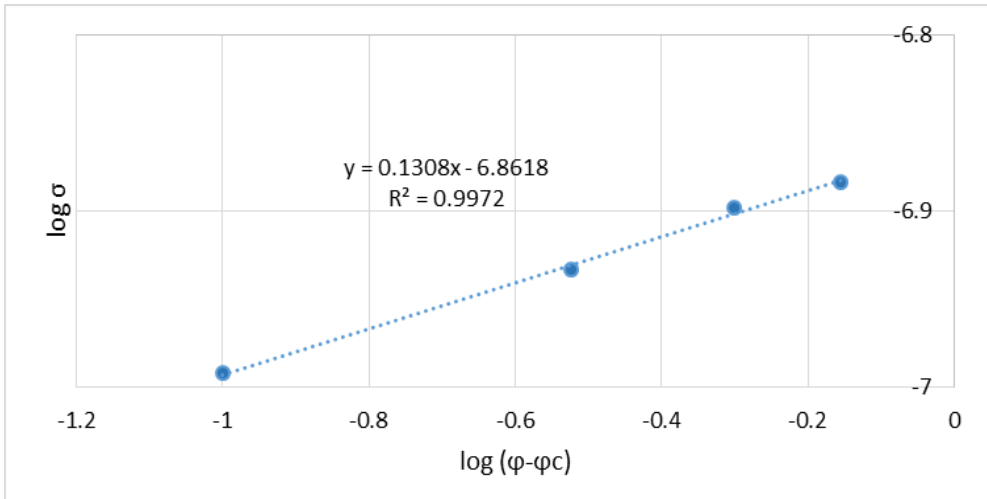

Fig. 2. Linear regression, $\log \sigma$ versus $\log \left(\varphi-\varphi_{c}\right)$. 


\subsection{Rheological properties}

Rheology studies the flow behavior of the material under the stress applied. The rheological properties of the nanocomposites were affected by the loading, aspect ratio and dispersion of the filler, polymer molecular weight, and interfacial interaction between the filler and polymer [3].

The molten of the PP/MWCNT nanocomposites was a non-Newtonian liquid that can be shown by the increasing frequency which decreased the viscosity as shown in Figure 3. The addition of MWCNT increased the viscosity of the nanocomposites because this filler affects the molecular movement of the polymer and consequently the nanocomposites become more viscous.

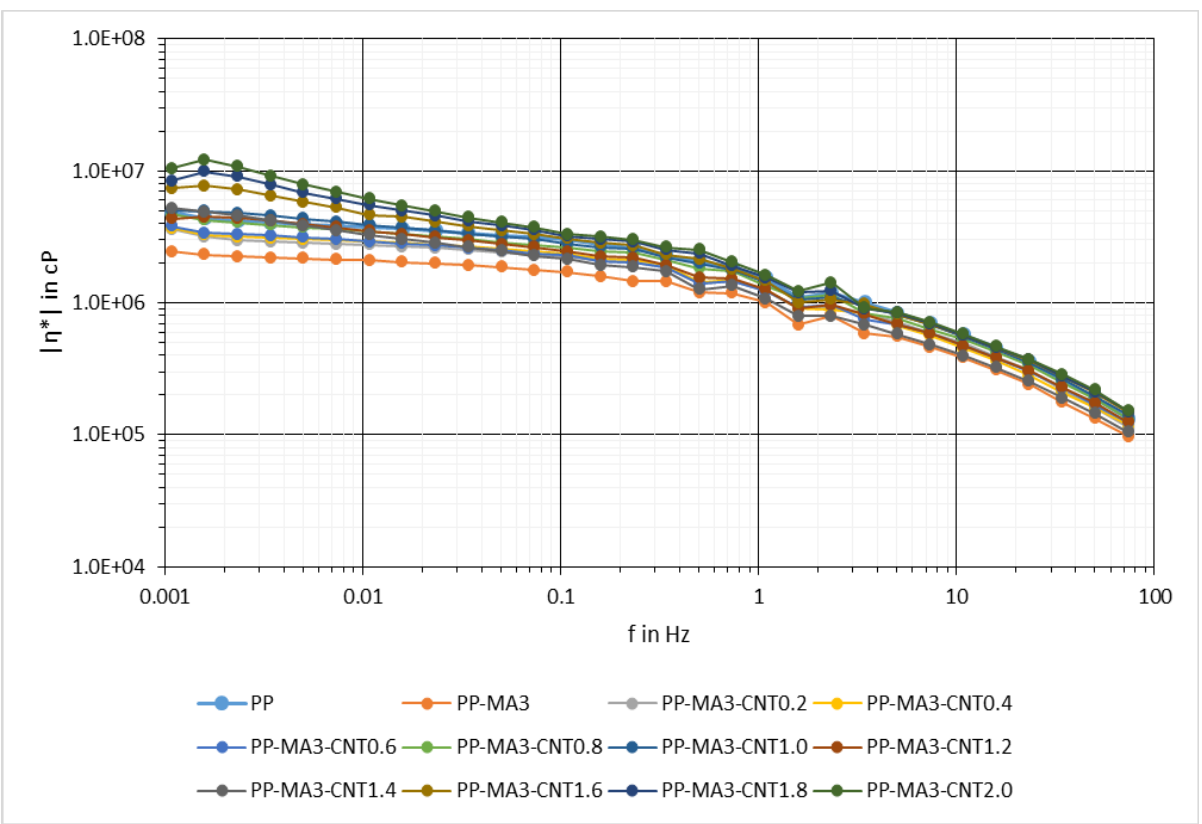

Fig. 3. Viscosity of PP/MWCNT as function of frequency at $180^{\circ} \mathrm{C}$.

The storage modulus ( $\left.\mathrm{G}^{\prime}\right)$ is the elastic solid-like behavior and the loss modulus (G”) is the viscous response of the PP/MWCNT nanocomposites. G' of these nanocomposites gradually increases with increasing frequency. This phenomenon indicated the transition of viscous liquid to solid-like behavior of the material.

Transition from rheological state to a solid-like behavior was obtained by the significant change of G' with increasing loading filler. Filler concentration in which the transition was occured is known as rheological percolation threshold [3]. Author found there was no significant increase on $\mathrm{G}^{\prime}$ but at $1.4 \mathrm{wt} \%$ of MWCNT there was an indication that the percolation threshold was observed. 


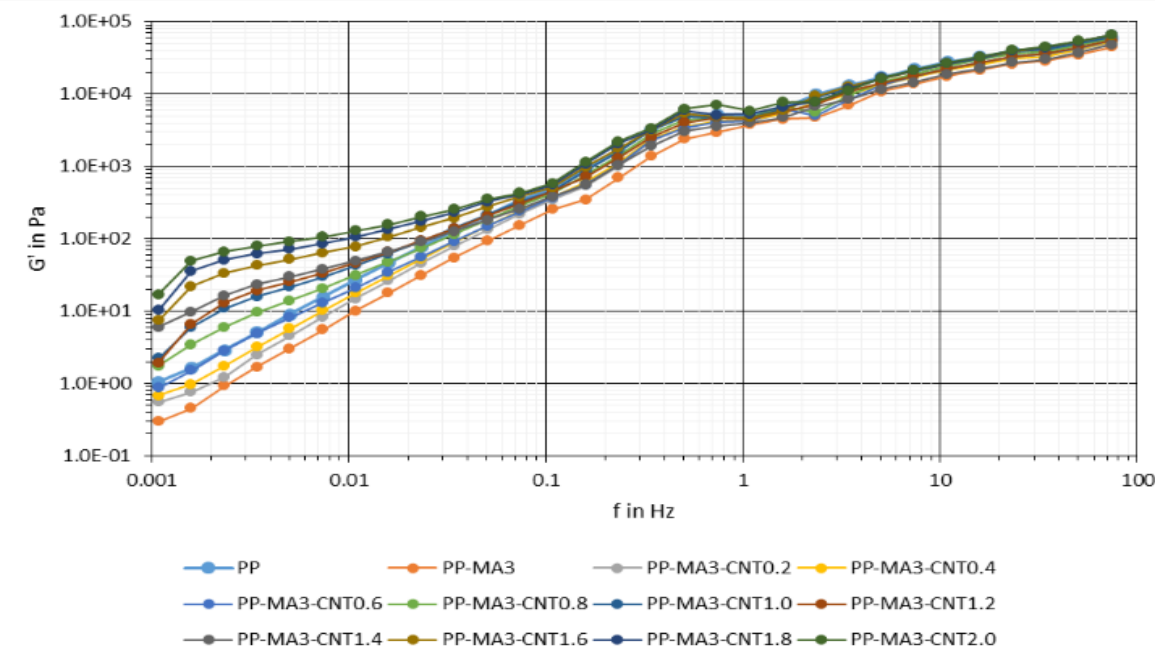

a

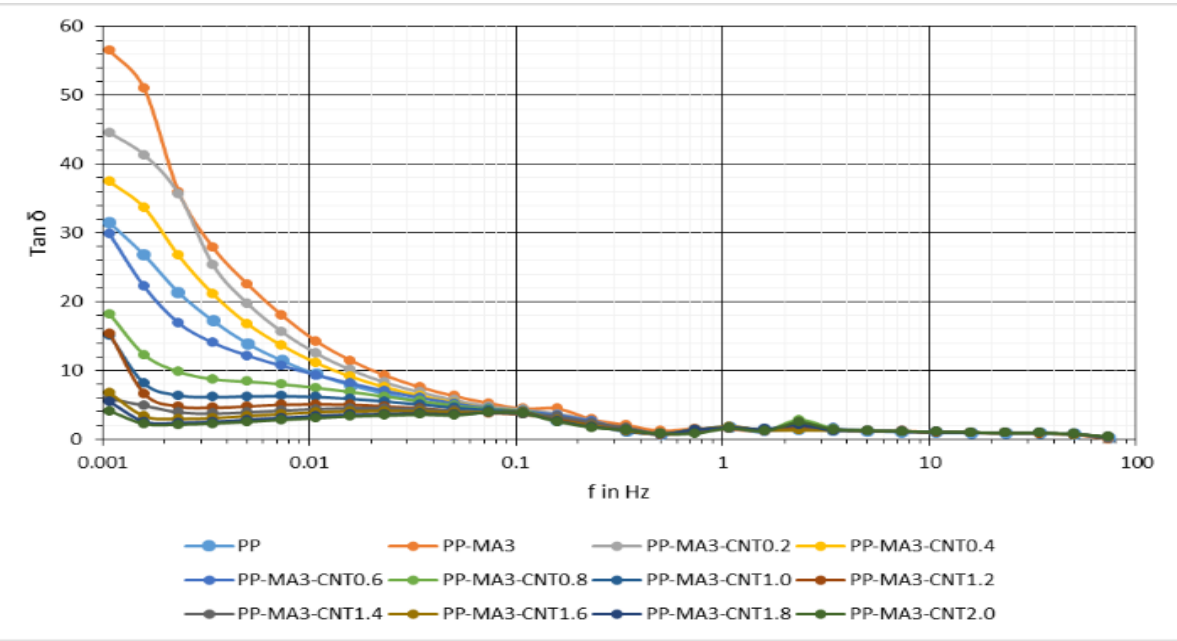

b

Fig. 4. Storage modulus (a) and phase angle (b) of PP/MWCNT as function of frequency at $180^{\circ} \mathrm{C}$.

In order to have better observation of the percolation threshold, the phase angle $(\tan \delta)$ was plotted against the frequency (Figure 4.b). Below the percolation threshold, $\tan \delta$ increased at low frequency because of liquid-like behavior. From this observation, the rheological percolation threshold of the nanocomposites was identified between 1.2 and 1.4 wt $\%$.

\subsection{Morphology}

The CNT was dispersed well in the nanocomposites as shown in Figure 5. There was no agglomeration observed in the PP/MWCNT. There were some techniques to obtain a good dispersion of CNT in polymeric matrix. One of the techniques was by applying the compatibilizer, in this work, PP-g-MA was used to disperse the CNT. In addition, high shear processing was utilized to improve the CNT dispersion. Good dispersion was achieved and expected to reduce percolation threshold of the nanocomposites. 


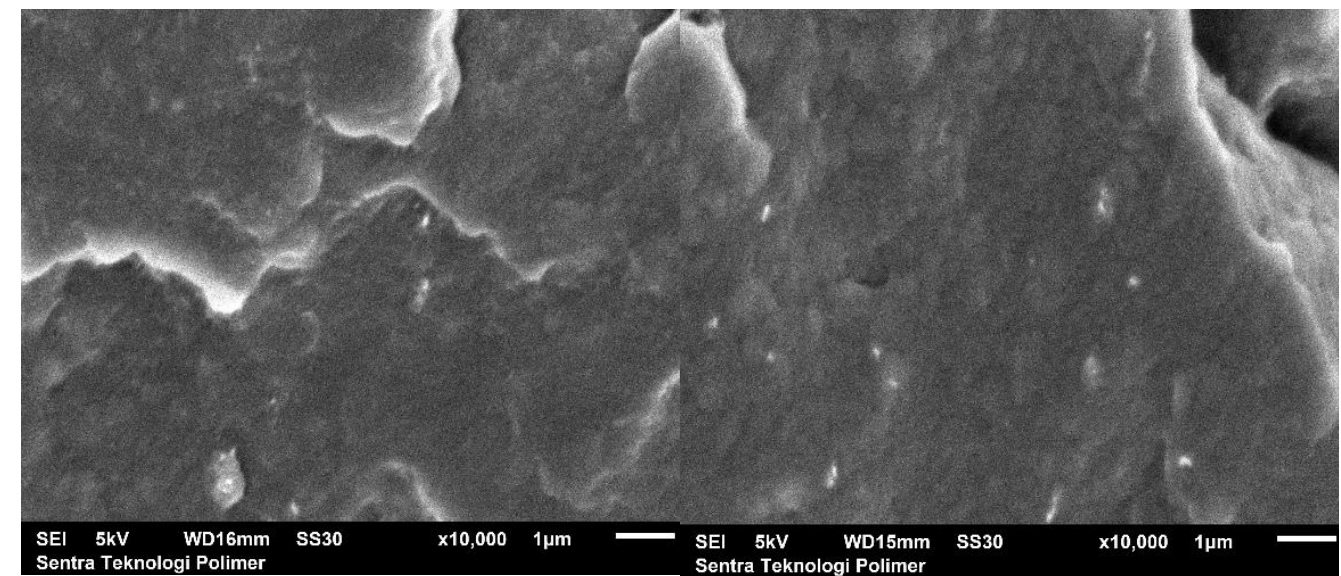

Sentra Teknologi Polimer PP-MA3-CNT0.2 Sentra Teknologi Polime
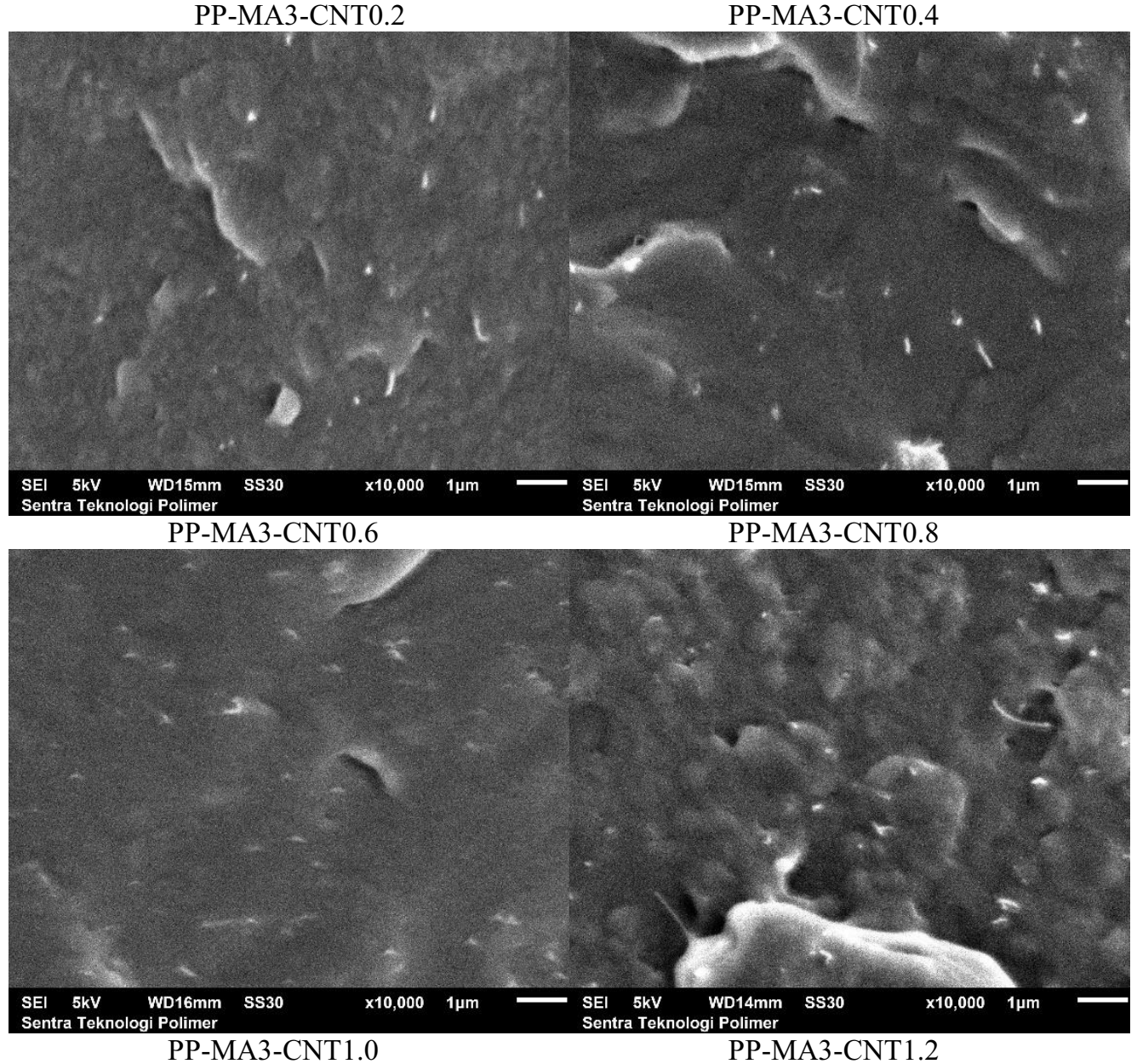

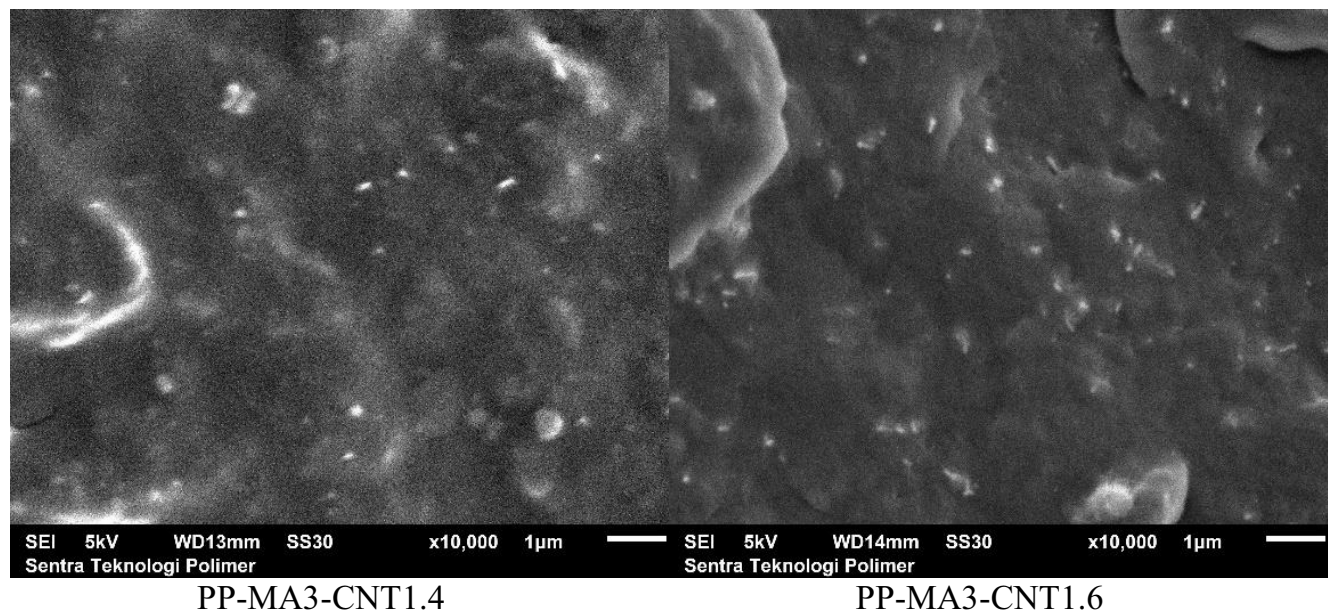

PP-MA3-CNT1.6

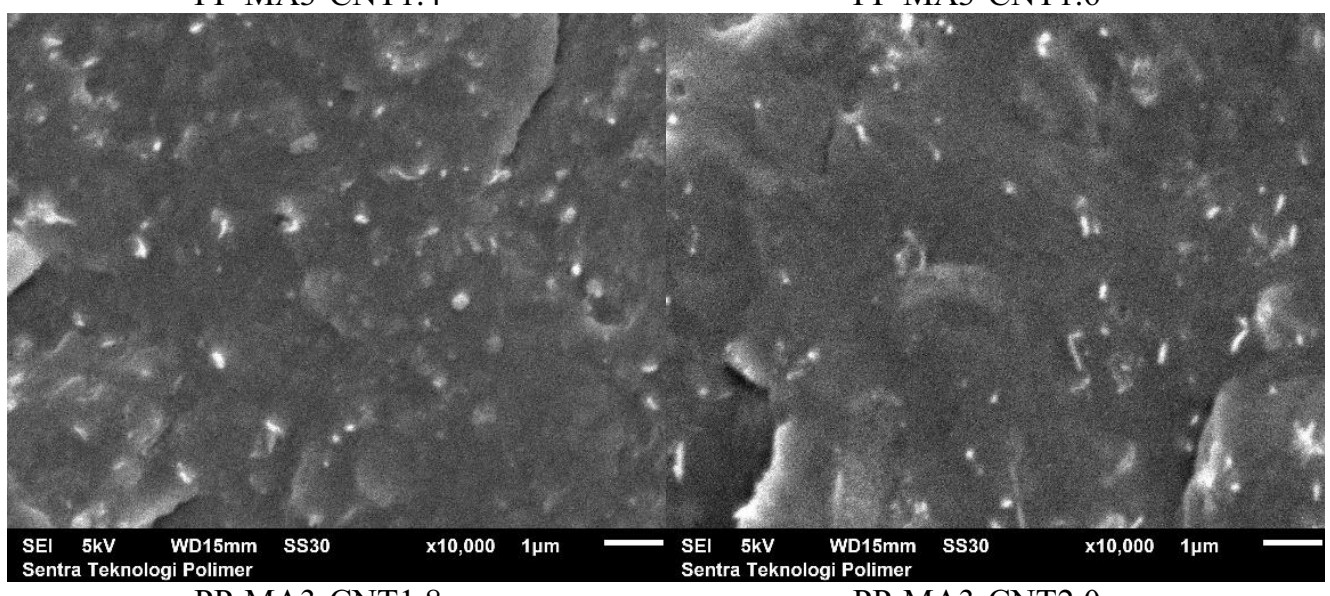

PP-MA3-CNT1.8

PP-MA3-CNT2.0

Fig. 5. Morphology of PP/MWCNT.

\section{Conclusions}

PP/MWCNT nanocomposites had been successfully prepared by melt mixing technique. Addition of MWCNT improved the electrical conductivity of the polypropylene. These nanocomposites had electrical percolation threshold at $1.3 \mathrm{wt} \%$. From rheological observation, it was noted that the solid to liquid transition occurred at $1.4 \mathrm{wt} \%$ of filler loading.

\section{References}

1. S. Iijima, Nature, 354, 56 (1991)

2. P. Verma, P. Saini, V. Choudhary, Mater. Des., 88, 269 (2015)

3. P.C. Ma, N.A. Siddiqui, G. Marom, J.K. Kim, Compos. Part A-Appl. S., 41, 1345 (2010)

4. I. Dubnikova, E. Kuvardina, V. Krasheninnikov, S. Lomakin, I. Tchmutin, S. Kuznetsov, J. Appl. Polym. Sci., 117, 259 (2010)

5. G. Mittal, V. Dhand, K.Y. Rhee, S.J. Park, W.R. Lee, J. Ind. Eng. Chem., 21, 11 (2015) 
6. K. Prashantha, J. Soulestin, M.F. Lacrampe, M. Claes, G. Dupin, P. Krawczak, Express Polym. Lett., 2 (10), 735 (2008)

7. M. Trujillo, M.L. Arnal, A.J. Muller, St. Bredeau, D. Bonduel, Ph. Dubois, I.W. Hamley, V. Castelletto, Macromolecules, 41, 2087 (2008)

8. R.S. Araujo, R.J.B. Oliveira, M.F.V. Marques, Macromol. React. Eng., 8, 747 (2014)

9. R. Kotsilkova, E. Ivanov, D. Bychanok, A. Paddubskaya, M. Demidenko, J. Macutkevic, S. Maksimenko, P. Kuzhir, Compos. Sci. Technol., 106, 85 (2015)

10. K. Zhou, S.Y. Gu, Y.H. Zhang, J. Ren, Polym. Eng. Sci., 8, 1 (2012)

11. Y.S. Shim, S.J. Park, Carbon Lett., 11 (4), 311 (2010)

12. S. Maiti, N.K. Shrivastava, S. Suin, B.B. Khatua, Express Polym. Lett., 7 (6), 505 (2013)

13. V. Levchenko, Y. Mamunya, G. Boiteux, M. Lebovka, P. Alcouffe, G. Seytre, E. Lebedev, Eur. Polym. J., 47, 1351 (2011)

14. W. Bauhofer, J.Z. Kovacs, Compos. Sci. Technol., 69, 1486 (2009) 